\title{
Driving innovation: Application of Linear Programming to improving farm systems
}

\author{
B.J. RIDLER ${ }^{1}$, J.M. RENDEL ${ }^{1}$ and A. BAKER ${ }^{2}$ \\ ${ }^{1} R D$ 1, Pio Pio \\ ${ }^{2}$ Murumuru Farms, RD, Raetihi \\ bjr@clear.net.nz
}

\begin{abstract}
This paper describes the concept of using Linear Programming (resource allocation modelling) to better understand and manage any pastoral system and to question the assumptions made of best practice given the limited knowledge available. Results from a case farm are presented to show typical outputs.
\end{abstract}

Keywords: beef, dairy, modelling, resource allocation, sheep, sustainability

\section{Introduction}

This is the age of the seven-second sound bite with the charge being led by TV news presentations. In this process, what the recipient tends to ignore is the sequence of events or facts behind the news and whether the sound bite actually conveys the appropriate information on which to create correct perceptions.

Some have observed recently that agricultural research and development has fallen into the same trap with slogans like "four percent productivity increase", "benchmarks", and "best practice", which create perceptions that some issues are vitally relevant without explaining why. There is therefore, need to define just what, for example, productivity really means and why should benchmarks be applied equally over all environments. The use of these snapshot phrases is a poor substitute for the understanding required of dynamic systems like farms. What is needed is the means to recognise and economically employ given resources in the most appropriate manner to achieve sustainable results.

The establishment of, and subsequent use of, best practice management is not often possible on a continuing basis owing to the practical difficulties of managing whole farm systems over successive years under varying climatic conditions. These difficulties also preclude any meaningful evaluation using replicated farms or farmlets owing to the need to vary many parameters between the different systems in order to optimise use of resources. Some modelling techniques can help but the spreadsheets and simulation models currently used to analyse the effects of improved feed production have limitations when evaluating the many alternatives possible in grazing systems.

There are various methods of increasing pasture production. But the issue is that the methods need to be justified in a practical, sustainable, biologically and economically robust manner. One means of justification is the use of models in which alternate ways of managing a farm can be compared. The purpose of this paper is to describe one type, the Linear Programme (LP).

\section{The model and the case farms}

\section{Background}

The LP approach optimises a function. It also considers all strategies without preconceptions or prejudices (Pannell 1997). Further information is then generated about the value of resources and relative performances of alternative activities (for example beef cows and calves versus a buying-in policy).

LP has been used previously to model farm systems (e.g., McCall 1999; Pannell 1997; Pollard 1972; Ridler 1988) but rarely as a means to improve actual farm systems (Ridler 1980, 1984, 1987). The discipline of this type of modelling is that the systems and the individual components that make up each system must be clearly defined. In this manner they can then be integrated together as part of an economic framework. Indeed, the LP approach is about the allocation of scarce resources (feed and land) to competing enterprises (Daellenbach 2001) in order to maximise the objective - in this case farm profitability - when there are constraints in the system (such as pasture grown, opening and closing pasture covers being equal, etc.).

Pannell (1997) identified as a major weakness of LP the need for skilled and knowledgeable people to apply and build LPs - in fact this was identified as a major factor in limiting the application of LP in the real world. This demands an interdisciplinary approach with continual reference to real farm systems.

\section{The case farms}

Over the past 10 years, a computer program has been constructed to allow best resource use on pastoral farms. This began as a project to better define the 
value and use of pasture on a sheep and beef farm (Case Study Farm 1) in order to establish a sustainable farm system (biologically and economically). This farm had been purchased in 1987 and after 2 years of trying to establish a profitable sheep and beef farm enterprise based on benchmark targets (such as average pasture cover at lambing, finishing policy, FxH cows, double suckling, pasture renewal, EFS/ ha), it was decided to revert back to scientifically sound first principles whilst developing a method to objectively assess possible combinations of resources on the farm. The modelling technique chosen (LP) allowed a clear indication of the best resources to use and their combinations under a range of variables (such as calving/lambing; weaning/dry off; sales/ culling; production and schedule, buy/sell prices) at various times of the year.

The Case Study 1 sheep and beef farm (460-ha hill country sheep and beef farm, 400m ASL, Mairoa Ash, $7600-8800 \mathrm{kgDm} / \mathrm{ha} / \mathrm{yr}$ ) acted as the catalyst for this model development and as a validation unit during the whole project.

Another farm (Case Study 2) is in a development stage where fertiliser, fencing and pasture improvement are required. The LP model has been used to explore many scenarios of different stock type and performance, and dates of calving/lambing and sales and to enter various best practice and benchmarking figures. Because the results are specific to this farm, the perceptions of what will occur have been analysed using real input prices and quantities supplied by the manager.

\section{Inputs to the model}

Feed input into the LP model consists of 2-weekly pasture growth rates and energy content, pasture utilisation by the stock, options for making and purchasing supplements and nitrogen application dates and responses. (Prototypes have been developed that allow evaluation of growing crops for green feed or silage).

Animal liveweight and liveweight gains/losses are included in 2-weekly intervals. For cows (beef and dairy) and ewes, liveweight cannot be mined (opening and closing liveweight must be equal). Calving/ lambing dates are inputs, as are drying-off dates (dairy), culling dates, weaning dates and percentages. Dairy cow milk production is also an input. These figures are used to calculate feed requirements for the classes of stock, using published energy requirements (AFRC 1993).

Relevant costs are also inputted (e.g., per cow costs, per ewe costs, cost of making or purchasing and feeding out supplement, costs of cattle purchases) as are product prices (milksolids, sheep and beef schedule, wool).

Values for typical farms by region are already entered for the initial model "SOLVE" and each analysis builds from the previous one. Various model runs can be saved as a basis for comparison as other management options are explored.

\section{Outputs from the model}

As part of the model function, a full stock reconciliation and feed budget can be reported. It can also report feed requirements for all classes of stock. The expected average pasture covers are presented for each 2-week period. The model maximises profit (variable income less variable costs).

For dairying, reports available include how many cows can be run, calving, culling and drying-off dates (along with the number of animals), whether to run youngstock on or off the farm, the amount of nitrogen to apply (and when), and the amount of supplement to make or purchase and when to feed it out. For the sheep and beef models, the lambing/calving dates are reported (along with number of ewes lambing or cows calving), number of beef weaners to purchase, dates to sell stock (prime or store), dates and amount of supplement made, purchased, and fed out, and dates and amount of nitrogen applied.

\section{Access to the model}

Adapting the concept to an Internet application allowed the many enhancements to the original base model to be accessed immediately without having to mail updates. Any farm with a phone (mobile, satellite or landline) can now access the technology. Thus the whole project culminated in an Internet based application (www.grazingsystems.co.nz) as a means to speed up and expand the ability to analyse individual farm systems. Suitable farms for modelling include dairy, beef, and sheep and beef farms; the model is continually being developed to incorporate added functions.

\section{Discussion}

By using a specific sheep and beef farm where inputs and outputs have been measured, it has become evident that production plateaus occur. These may be overcome by various means (but at added capital cost and risk) or by better use of the resources involved.

Use of the LP model has led Case Study Farm 1 towards a new system of how feed is grown and utilised 
and a refined system to make the best use of it with breeding cows and ewes. This combination can be shown to be competitive with more intensive systems (both technology and management) in terms of the return for the resources used. Actual farm income has increased every year for the past 10 years when use of the model started.

Experience from the Case Study 2 farmer shows that resource allocation modelling has led to a greater confidence in decision making and allowed a wider, systems-orientated view, to be developed. This is because of the ability to quickly and easily change parameters within the LP model and solve many slightly different (pasture growth/quality, liveweight gain, pasture cover constraints, lambing/calving dates) scenarios.

It may come as a surprise to many that widely varying systems can return similar profits for the same resource base. Labour, soil, pasture, parasites and repairs and maintenance costs differ between the management systems, but the ability to use pasture at the most appropriate time is the key factor. There is a very flat optimal resource use curve apparent in pasturebased farming.

If the feed barrier is broken by enhancing the main growth period of the year, the requirements to make and feed supplement or purchase stock outweigh the perceived advantage of this extra feed. It may be far better to use strategic nitrogen, adjust the sale strategy, grow stock differently and allow added total pasture accumulations, than to grow more grass. It may also be more rational and profitable to hold lambing percent at around $120-140 \%$ than to push towards $200 \%$ as analysis from Case Study Farm 1 showed (Table 1).
The results from using the LP can be simply presented using output files. But the basis for the differences can prove difficult to explain to those accustomed to pure research. For example, by improving lambing percentage, pasture growth rates may remain the same but differences in pasture quality, number of stock, average pasture covers in each period, sale time and weights and even different mixes of stock type will occur. That such changes may not ultimately lead to a greatly different dollar income can be used to dismiss the results as unimportant. But this also misses the point. The model results require explanation and also an understanding of what is happening within the farm as a system.

\section{Conclusion}

The use of this LP model dispels perceptions and demands reality. The output allows the scenarios to be studied and a logical answer as to "why?" to be determined. The systems approach to whole-farm modelling also shows that the consequences of eliminating under-utilised resources may not turn out to be as beneficial as expected (Daellenbach 2001).

Any barrier that the title to the Conference session represents would seem to be more a barrier to objective thought ("the prevalent attitudes of agricultural researchers and their evaluators") (Edward-Jones 2001) towards certain types of research and a failure to recognise that the systems to best manage pasture have barely been addressed. There is a failure to understand what systems management in a pastoral sense really entails and too often, an inability to acknowledge this failure. LP not only provides a logical framework within which these barriers can be

Table $₫ 1$ Summary of the effects on Case Study 1 farm (460-ha mixed sheep and beef farm) of increasing weaning percentage.

\begin{tabular}{|c|c|c|c|c|}
\hline & $105 \%$ & $\begin{array}{l}120 \% \\
\text { Lamb wea }\end{array}$ & $\begin{array}{c}\text { centage) } \\
160 \%\end{array}$ & $200 \%$ \\
\hline Cows calving & 331 & 325 & 311 & 313 \\
\hline \multicolumn{5}{|l|}{ Sales } \\
\hline Bulls prime & 145 & 142 & 136 & 137 \\
\hline (sale date) & Mar 21/Apr 18 & Mar 21/Apr 18 & Apr 18 & Apr 18 \\
\hline Heifers prime & 78 & 77 & 74 & 74 \\
\hline (sale date) & Mar 21 & Jan 24 & Feb 21 & Feb 21 \\
\hline Ewes lambing & 1,986 & 1,953 & 1,869 & 1,878 \\
\hline \multicolumn{5}{|l|}{ Lamb sales } \\
\hline Store ram & $1,042 / 28 \mathrm{~kg}$ & $1,171 / 26.6 \mathrm{~kg}$ & $1,391 / 24.5 \mathrm{~kg}$ & $1,490 / 23.3 \mathrm{~kg}$ \\
\hline Store ewe & $530 / 26 \mathrm{~kg}$ & $668 / 24.6 \mathrm{~kg}$ & $1,013 / 22.3 \mathrm{~kg}$ & $1,018 / 21.1 \mathrm{~kg}$ \\
\hline Prime ram & 0 & 0 & 98 & 11 \\
\hline Prime ewe & 0 & 0 & 0 & 0 \\
\hline \multicolumn{5}{|l|}{ Variable income - variable costs } \\
\hline Total & $\$ 345,268$ & $\$ 350,042$ & $\$ 367,549$ & $\$ 360,940$ \\
\hline Per ha & $\$ 822$ & $\$ 833$ & $\$ 875$ & $\$ 859$ \\
\hline Per ha difference from $105 \%$ & 0 & $\$ 11$ & $\$ 53$ & $\$ 37$ \\
\hline
\end{tabular}


addressed, but as importantly, can aid in the research, implementation and management of specific farm systems.

\section{REFERENCES}

AFRC 1993. Energy and protein requirements of ruminants. An advisory manual prepared by the AFRC Technical Committee on Responses to Nutrients. CAB INTERNATIONAL, Wallingford, UK.

Daellenbach, H.G. 2001. Systems thinking and decision making: a management science approach. REA Publications, Christchurch, New Zealand.

Edwards-Jones, G. 2001 Should we engage in farmerparticipatory research in the UK? Outlook on AGRICULTURE 30: 129-136.

McCall, D.G. et al. 1999. Optimised Grazing Systems in the Northeast United States and New Zealand. 1. J. Dairy Science 82: 1795-1807.

McCall, D.G.; Clark, D.A. 1999. Optimised Dairy Systems in the Northeast United States and New Zealand. 2. J. Dairy Science 82: 1808-1816.
Pannell, D.J. 1997. Introduction to practical linear programming. John Wiley \& Sons Inc., New York. 333 pp.

Pollard, V.J. 1972. The profitability of nitrogen fertiliser applications on seasonal supply dairy farms. Technical Paper 10: Department of Agricultural Economics and Farm Management, Massey University, New Zealand.

Ridler, B.J. 1980. Use of a linear Programming Model on a Large Scale Dairy Farm.

Workshop on Application of Computers to Agriculture. Launceston, TCAE Tasmania.

Ridler, B.J.; Hurley, E.M.; Stachurski, L.J. 1984. The management policy for Massey's Large Herd. Proceedings of the Ruakura Farmers Conference.

Ridler, B.J. 1987. The use of a pastoral computer model - a learning experience. Proceedings of the New Zealand Society of Animal Production 47: 43-44.

Ridler, B.J. 1988. Incorporation of Matua praire grass into grazing systems. Proceedings of the New Zealand Grassland Association 49: 181-184. 